UCRL-ID-120471

\title{
Retardation of Volatile Organic Compounds in Ground Water in Low Organic Carbon Sediments
}

\author{
Fredric Hoffman
}

April 1995

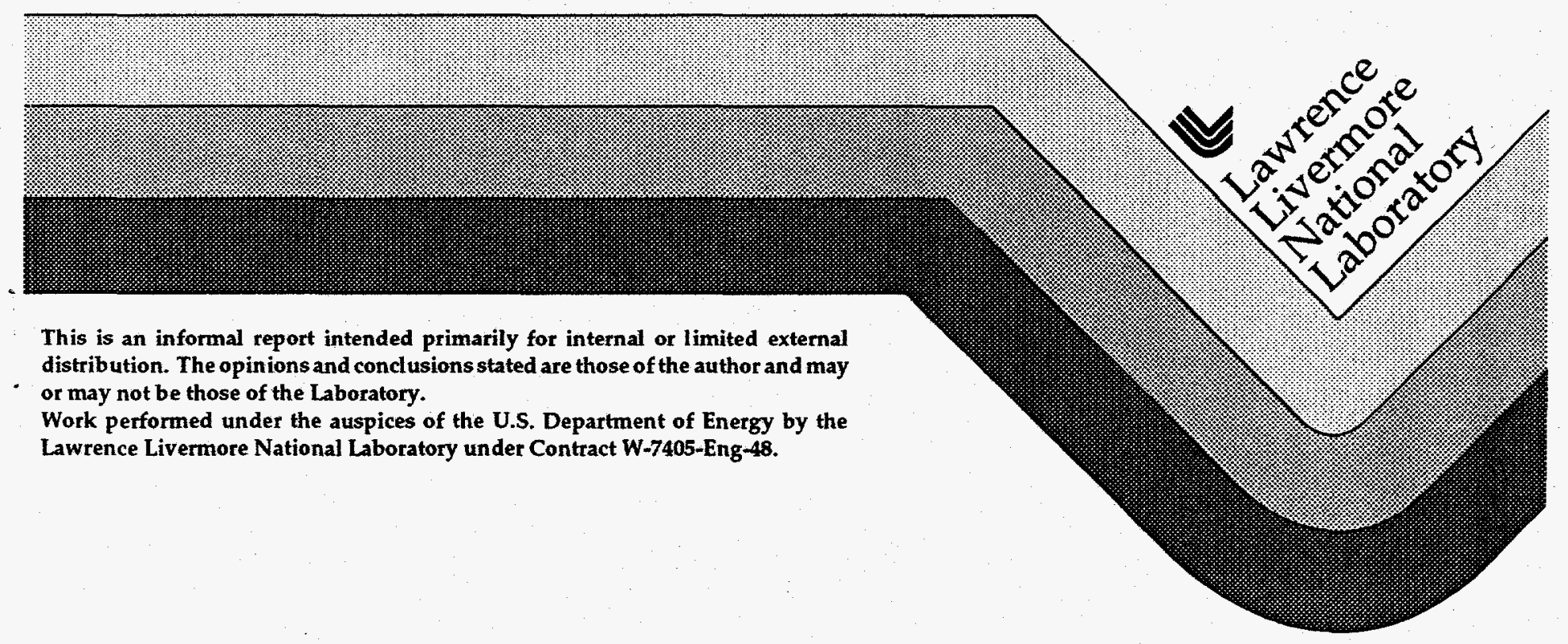




\section{DISCLAIMER}

This document was prepared as an account of work sponsored by an agency of the United States Government. Neither the United States Government nor the University of California nor any of their employees, makes any warranty, express or implied, or assumes any legal liability or responsibility for the accuracy, completeness, or usefulness of any information, apparatus, product, or process disclosed. or represents that its use would not infringe privately owned rights. Reference herein to any specific commercial product, process, or service by trade name, trademark, manufacturer, or otherwise, does not necessarily constitute or imply its endorsement, recommendation, or favoring by the United States Government or the University of California. The views and opinions of authors expressed herein do not necessarily state or reflect those of the United States Government or the University of California, and shall not be used for advertising or product endorsement purposes.

This report has been reproduced

directly from the best available copy.

Available to DOE and DOE contractors from the

Office of Scientific and Technical Information

P.O. Box 62, Oak Ridge, TN 37831

Prices available from (615) 576-8401, FTS 626-8401

Available to the public from the

National Technical Information Service

U.S. Department of Commerce

5285 Port Royal Rd.,

Springfield, VA 22161 


\section{DISCLAIMER}

Portions of this document may be illegible in electronic image products. Images are produced from the best available original document. 
Interim Report

Retardation of Volatile Organic Compounds in Ground Water

in Low Organic Carbon Sediments

Fredric Hoffman

April 1995

Approved by

\section{Dr. Daniel Ronen}

Feinberg Graduate School

Weizmann Institue of Science 


\section{Retardation of Volatile Organic Compounds in Ground Water \\ in Low Organic Carbon Sediments}

\section{Introduction}

All analyses of contaminant transport in ground water are very sensitive to the retardation factor, i.e., the relationship of the linear velocity of the ground water to the linear velocity of the contaminant. Equation (1) is used for calculating the retardation factor (R) (After Freeze and Cherry, 1979).

$$
R=V_{w} / V_{c}=1+\left(\rho_{b} / n\right)\left(K_{d}\right)
$$

where: $\quad V_{\mathrm{W}}=$ velocity of the ground water

$\mathrm{V}_{\mathrm{c}}=$ velocity of the contaminant

$\rho_{b}=$ bulk density of the porous medium

$\mathrm{n}=$ porosity of the porous medium

$K_{d}=$ distribution coefficient

The variability of the bulk density/porosity term, in permeable unconsolidated sediments, is much less than that of $K_{d}$, making $K_{d}$ the dominant variable (Curtis et al., 1986). $K_{d}$ is often considered to be a measure of the sorption of the contaminant onto the matrix material and in these circumstances is defined as the concentration of the contaminant on the solid in units of weight/weight divided by the concentration of the contaminant in the liquid in units of weight /volume. For those sediments containing $>0.1 \%$ organic carbon, absorption of volatile organic compounds (VOCs) into the matrix of the organic materials present is recognized as the dominant retarding mechanism (Karickhoff, 1984; Schwarzenbach and Giger, 1985). In sediments containing $<0.1 \%$ organic carbon, however, the mechanisms of apparent retardation are less well understood. 
I postulate that adsorption onto the surfaces of the aquifer matrix materials is only one of the processes that results in the apparent retardation of contaminants in ground water in unconsolidated sediments. A partial list of other possible mechanisms includes: hydrodynamic dispersion; abiotic and/or biotic degradation (Curtis et al., 1986; Mackay et al., 1986); matrix diffusion; partitioning to organic carbon; and diffusion into and entrapment/retention of the contaminant in constricted or dead-end pores. The aim of this work is to study the relative importance of the above mentioned processes in defining the $\mathrm{K}_{\mathrm{d}}$ of VOCs in sediments having a low organic carbon content.

Retardation has been observed in the field as well as in the laboratory and influences the leading edge of a VOC contaminant plume as well as the trailing edge of a plume during attempted ground water remediation. There is empirical evidence from a number of remediation sites (U.S.EPA, 1989) that demonstrates that aquifer cleanup by pump and treat techniques takes long time periods, and that aquifers that appear to have been cleaned often become re-contaminated following the cessation of pumping (Travis and Doty, 1990). There has also been a series of carefully controlled experiments in the relatively homogenous sands of the Borden Aquifer in Canada (Mackay et al., 1986) that have shed some light on sorption and retardation rates and processes.

In addition, there have been a number of hypotheses that have been advanced to explain the observed behavior of these chemicals. These include; chemical heterogeneities within aquifers (Ronen et al., 1987), diffusion of contaminants into and out of heterogeneous geologic materials (Hoffman, 1993a; Wilson, 1995), sorption/desorption hysteresis (Roberts et al., 1986; Domenico and Schwartz, 1990), density induced flows (Shincariol and Schwartz, 1990; Hoffman et al., 1993; Istok and Humphrey, 1993), contaminants left in zones of stagnation and in dewatered areas within cones of depression in phreatic aquifers (Hoffman, 1993b), and the orientation of the axis of the contaminant plume with respect to the location of the extraction and monitor wells (Hoffman, 1993a). One, some, or all of these phenomena may be significant to the rate of contaminant removal during aquifer cleanup. 
The purpose of this research is to gain an understanding of the most important mechanisms that control the retardation of VOCs in the absence of organic carbon and how the geologic characteristics of the sediments influence the kinetics of these mechanisms. At the pore scale I will attempt to discriminate between adsorption onto aquifer matrix materials and diffusion into low mobility pore spaces. At the geologic feature scale, I will attempt to determine the relative importance of large scale aquitards as possible sinks, during plume passage, and later as sources of VOC contamination during aquifer cleanup. I will demonstrate that retardation of VOCs in low organic carbon unconsolidated sediments is not simply the result of sorption, as has been assumed up to now, but is indeed the result of a complex interaction of the mechanisms described above. In fact, it may be that sorption plays only a minor role under these conditions and that diffusion controlled mechanisms are dominant.

\section{Progress to date}

\section{Column Experiment}

An initial column experiment has been completed using several new technologies. This experiment has provided baseline conditions and parameters that can be achieved in a laboratory column, such as porosity, hydraulic conductivity, and $\mathrm{K}_{\mathrm{d}}$, and will be utilized in ongoing experiments. The experiment also served to help develop our laboratory techniques to minimize volatile losses during the experiment. Such techniques as the use of gas-tight syringes in the syringe pump and improved sample collection techniques will improve the rigor of additional experiments.

The column was designed to perform VOC retardation tests on geological materials. Since the sorption tests were to be evaluated based on the retardation of the contaminant through the column, the column was designed to approach complete and uniform contact of the contaminated water with the sediment and to minimize preferential flow through the sediments or along the boundaries of the column. In addition, the sediment was to be compacted to approximate field 
conditions. Another design constraint of the column was to minimize contaminant sorption on the column construction materials.

The sediment used in the column was designed to approximate a low organic carbon, fineto medium-grained sand of known grain-size distribution. To achieve this, sand from the Mektesh Gadol, in the Northern Negev Desert of Israel, was acid washed, sieved to three fractions, and the three fractions were recombined in equal parts by weight. The bulk density and porosity of the sand were determined gravimetrically and the hydraulic conductivity was measured with a constant head flow test. The final bulk density was $1.84 \mathrm{~g} / \mathrm{cc}$, the porosity was 0.27 , and the hydraulic conductivity was $2.1 \times 10^{-2} \mathrm{~cm} / \mathrm{sec}$.

To ensure that the column met its design requirements, flow tests were evaluated using magnetic resonance imaging (MRI) (Hoffman et al., 1993). Three iterations of packing and compaction efforts followed by MRI evaluations were necessary before we were satisfied that the column had minimal preferential flow paths and minimal air bubbles.

The MRI images revealed the heterogeneities within the column. These heterogeneities were expected even though I was trying to create a homogeneous media. The processes that caused the heterogeneities during the column packing are the same processes that cause heterogeneous deposition of natural sediments. Small but observable irregularities in the flow could be seen in sequential images as the tracer passed through the column, and were interpreted as resulting from small changes in hydraulic conductivities. Vertical slice images through the column also clearly showed the effect of the differences in density between the water and the tracer solution. By measuring the velocity of the tracer through the column and applying the known velocity of the water to equation 2 , I was able to calculate the retardation and $K_{d}$ for the tracer. When the tracer had completely invaded the column, additional images were taken as the column was flushed with fresh water. Following 1.5 pore volumes of fresh water flow, some sorbed tracer could be seen remaining within the finer-grained areas of the column. While the behavior of this polar metallic ion can not be compared to that of the non-polar hydrophobic VOCs, that are the subject of this 
study, this exercise does present new possibilities for the use of MRI in studying pore scale contaminant transport.

An image of a slice through the center of the column is shown in Figure 1. Two of the more prominent features of the packing process are labeled A and B on the figure. These experiments demonstrated the potential value of MRI in conducting ground water contaminant fate and transport studies in packed columns. The column packing and bubble avoidance and removal techniques that were developed with the aid of the MRI will be used in our future column experiments.
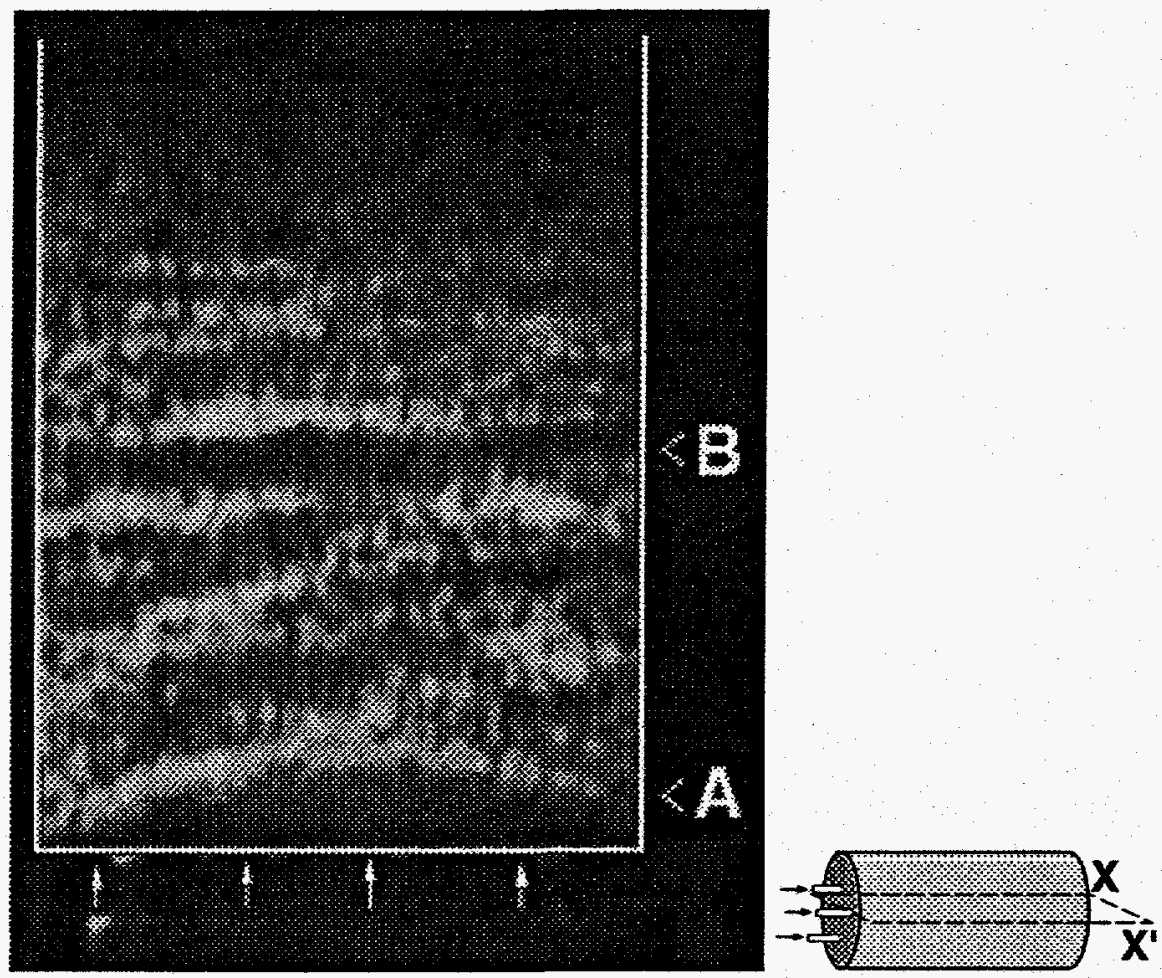

Figure 1. This MRI image was taken of the water saturated column before the introduction of the tracer. Note the prominent light-colored coarser-grained feature $(A)$ at the entrance of the column, and the dark-colored finer-grained feature $(B)$ about $3 \mathrm{~cm}$ into the column. Six cm of the sand are shown in this image.

The VOC used in the retardation experiment was trichloroethylene (TCE) with $\mathrm{NaCl}$ in ${ }^{18} \mathrm{O}$ depleted water as conservative tracers. The breakthrough curves for the TCE and the tracers were compared and retardation and distribution coefficients were determined from equation 1. 
Two experiments were conducted. TCE analysis of the water exiting the column was accomplished using an on-line fiber-optic based sensor, chloride was analyzed by high pressure liquid chromatography (HPLC), and ${ }^{18} \mathrm{O}$ by mass spectrometry. When equation (1) was applied to the results, the first experiment yielded a TCE $K_{d}$ of $0.05 \mathrm{ml} / \mathrm{g}$ and the second experiment, 0.11 $\mathrm{ml} / \mathrm{g}$.

In order to provide a point of comparison for these column experiment values, I applied the $\mathrm{K}_{\mathrm{d}}$ determination method proposed by Piwoni and Banerjee (1989). This method is based upon the octanol / water partition coefficient $\left(\mathrm{K}_{\mathrm{OW}}\right)$ for sediments containing less than $0.1 \%$ total organic carbon. This method is shown in equation (2), and Piwoni and Banerjee (1989) claim that it should be accurate within a factor of two or three.

$$
\begin{aligned}
& \log \mathrm{K}_{\mathrm{d}}=1.01 \log \mathrm{K}_{\mathrm{OW}}-3.46 \\
& \text { where: } \quad \mathrm{K}_{\mathrm{OW}}=\text { Octanol } / \text { Water partition coefficient }
\end{aligned}
$$

Applying the values of $\mathrm{K}_{0 \mathrm{w}}$ for TCE taken from Schwarzenbach and Giger (1985) to equation (2) provided an estimated $\mathrm{K}_{\mathrm{d}}$ for TCE of $0.07 \mathrm{ml} / \mathrm{g}$. This value falls nicely between the two values from the column experiments.

The results of the first experiment are shown in Figure 2. The failure of the TCE breakthrough curve to achieve higher concentrations during the time frame of this experiment is the result of rate limited sorption, sequestration of TCE due to other retarding processes, and volatile losses during the sample collection.

The TCE analyses were conducted on line using a new fiberoptic sensor based on the rate of change of light absorption by a reagent which changes color in the presence of TCE (Angel et al., 1989; Milanovich et al, 1991). Use of the fiber-optic based sensor provided us with quick, real-time TCE analyses that allowed us to establish column baseline parameters to be applied to the more rigorous column experiments now underway. 


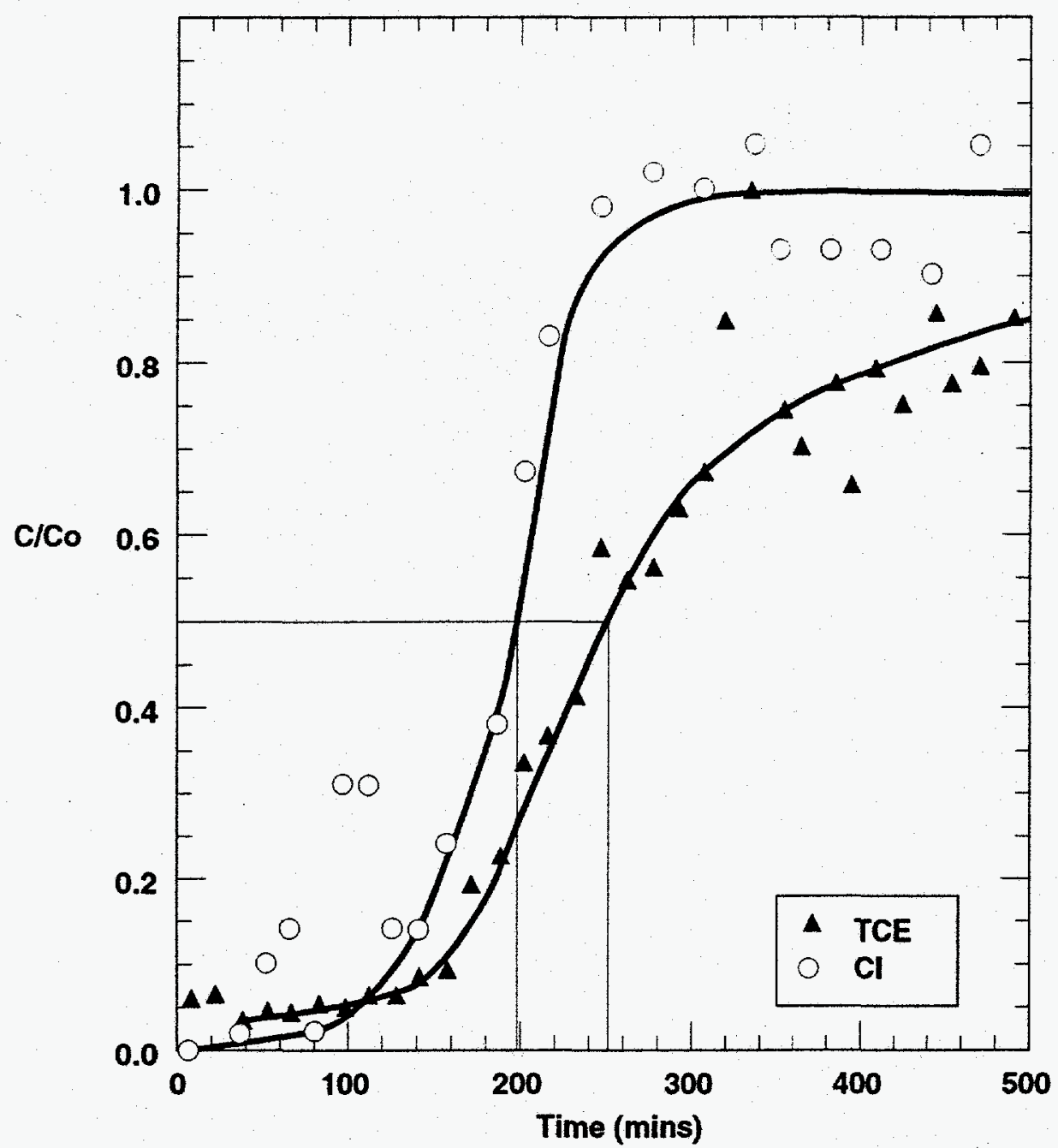

Figure 2. TCE and chloride breakthrough curves from the first TCE sorption experiment. Application of equation 1 yields an $R$ of 1.34 and a $K_{d}$ of $0.05 \mathrm{ml} / \mathrm{g}$.

\section{Distribution coefficients from field investigation data}

In an effort to develop a method to determine $\mathrm{K}_{\mathrm{d}} \mathrm{s}$ in the field and to learn more about the natural distribution of $\mathrm{K}_{\mathrm{d} S}$ in a plume of contaminated ground water, the tetrachloroethylene (PCE) and TCE data from 240 boreholes at Lawrence Livermore National Laboratory (LLNL) were examined. The LLNL sediments are all low $(<0.1 \%)$ in organic carbon. Saturated sediment samples collected and analyzed during drilling, and water samples collected and analyzed following the construction of wells in the same boreholes, were used in the analysis. The saturated sediments 
were collected by the method published by Hoffman and Dresen (1990). This method allows the collection of saturated sediment samples without cross-contamination from elsewhere in the vertical profile of the borehole. The water samples are taken from the screened interval of the well that is ultimately constructed in each borehole. The water samples and the saturated sediment samples that came from the same screened interval were compared. The resulting values along with estimates of the amount of porewater displaced by drilling fluids during drilling and the physical characteristics of the sediment sample were processed by the mass balance equation (3) for $K_{d}$.

$$
\mathrm{K}_{\mathrm{d}}=\left[\left(\left(\mathrm{Css} *\left(\rho_{\mathrm{b}}+\mathrm{n}\right)\right)-(\mathrm{Cw} * \mathrm{n} * \mathrm{Rpw})\right) / \rho_{\mathrm{b}}\right] / \mathrm{Cw}
$$

where: $\quad$ Css $=$ concentration in saturated sediment $(\mu \mathrm{g} / \mathrm{kg})$

$$
\begin{aligned}
& \rho_{\mathrm{b}}=\text { bulk density }(\mathrm{kg} / \mathrm{L}) \\
& \mathrm{n}=\text { porosity } \\
& \mathrm{Cw}=\text { concentration in well water }(\mu \mathrm{g} / \mathrm{L}) \\
& \mathrm{Rpw}=\% \text { remaining pore water after displacement } / 100
\end{aligned}
$$

This method has two significant uncertainties. The first concerns the question of how representative the well water is of the porewater in the saturated sample. While the porewater comes from a $75 \mathrm{~mm}$ long core sample, the well water sample is taken from a two to three meter long screened area of the aquifer. In addition, the core sample is taken during drilling while the water sample is taken following well development, days or weeks later. The second uncertainty concerns the amount of core sample porewater that is displaced by the drilling fluid during drilling. While I have not been able to fully resolve these uncertainties, I have attempted to address them.

To help decrease the uncertainty in the representativeness of the well water to the pore water, I analyzed the variability of the well water with time. Selecting a high and a low value, I calculated two $\mathrm{K}_{\mathrm{d} S}$ and reported the range. To help resolve the issue of porewater displacement, we extracted porewater from a core sample by centrifugation and analyzed the inorganic chemistry 
and compared it to that of the drilling fluid and to well water. For the sample analyzed, there was approximately $80 \%$ porewater displacement by the drilling fluid. This was the value I used in all of the $\mathrm{K}_{\mathrm{d}}$ calculations.

In spite of these remaining uncertainties, when all of the approximately $150 \mathrm{~K}_{\mathrm{d}} \mathrm{s}$ for both TCE and PCE were analyzed, they appeared to be lognormally distributed, and the harmonic mean of the $\mathrm{K}_{\mathrm{d}}$ (PCE $0.1 \mathrm{ml} / \mathrm{g}$; TCE $0.05 \mathrm{ml} / \mathrm{gr}$ ) agreed favorably with the $\mathrm{K}_{\mathrm{d}}$ determined in the column experiment and with the $\mathrm{K}_{\mathrm{d} S}$ in low organic carbon sediments found at the Borden site (Curtis et al., 1986).. In addition, there was close agreement between the $\mathrm{K}_{\mathrm{d}} \mathrm{s}$ of the different sediments, as described by the field geologist (Table 1.)

\section{TABLE 1. Kd Determinations for PCE and TCE $(80 \%$ Pore water displacement)}

\begin{tabular}{lcccc}
\hline & Gravel & Sand & Silt & All Data \\
\hline PCE (132 Kds) & & & & \\
\hline Average Range & & & & \\
Average & $0.4-1.16$ & $0.25-0.76$ & $0.21-0.71$ & $0.27-0.81$ \\
Standard Deviation & 0.68 & 0.39 & 0.4 & 0.44 \\
Harmonic Mean Range & 0.9 & 0.48 & 0.61 & 0.62 \\
Harmonic Mean & $0.05-0.27$ & $0.03-0.17$ & $0.02-0.19$ & $0.03-0.19$ \\
& 0.12 & 0.09 & 0.1 & 0.1 \\
TCE (124 Kds) & & & & \\
Average Range & & & $0.10-0.34$ & $0.19-0.27$ \\
Average & $0.22-0.51$ & $0.18-0.50$ & 0.16 & 0.27 \\
Standard Deviation & 0.31 & 0.27 & 0.2 & 0.32 \\
Harmonic Mean Range & 0.32 & 0.33 & $0.02-0.16$ & $0.03-0.15$ \\
Harmonic Mean & $0.06-0.17$ & $0.03-0.14$ & 0.06 & 0.05
\end{tabular}

The $\mathrm{K}_{\mathrm{d}}$ for the VOCs in the Borden aquifer materials (Curtis et al., 1986), the column experiment described above, and the $\mathrm{K}_{\mathrm{d}} \mathrm{s}$ estimated from the field investigation data also described above, all fall within the range predicted by the Piwoni and Banerjee (1989) method. This finding appears to indicate that VOC $\mathrm{K}_{\mathrm{d} S}$ in low organic carbon permeable aquifer materials are dependent on the chemical characteristics of the VOC and independent of the geologic grain size of the aquifer materials. This is contrary to the commonly accepted theory that retardation of VOCs in ground 
water in low organic carbon sediments is primarily the result of sorption, and that sorption is a function of surface area.

\section{Multi-Laver Sampler Experiment}

A preliminary multi-layer sampler experiment (DMLS) was performed in well W-415, a contaminant extraction well at LLNL. The well is screened through the entire contaminated vertical interval $(25 \mathrm{~m})$ and spans four permeable zones and the intervening lower permeability zones. In this experiment, the four permeable zones were simultaneously sampled with cells at $10 \mathrm{~cm}$ intervals. The intervening low permeability zones were not sampled. The results of this experiment are shown in Figure 3. This well is located near the source of the contamination and as expected the contaminant concentrations were higher in the upper zones than in the lower ones. An interesting feature of the second and third profiles in Figure 3 is that the PCE concentrations are highest in the upper part of each zone and steeply decline with depth. One possible interpretation of this decline is that the coarse-grained zones are being continually cleaned by the pumping well and that new contamination continues to diffuse into the zone from the lower permeability zone, immediately above.

This application of the DMLS is the first time that the instrument has been deployed in a wire-wrapped well screen that extends through multiple permeable and low permeability geologic zones. The quality of the profiles in Figure 3 provide encouragement that performing experiments with the DMLS will provide data regarding the transport of VOCs across geologic contacts.

\section{Program for further investigation}

This research will consist of laboratory packed column experiments to examine and compare the retardation rates for the leading and trailing edges of a VOC contaminant plume; laboratory diffusion experiments to determine the rate of VOC diffusion into different geologic materials; comparison of distribution coefficients $\left(\mathrm{K}_{\mathrm{d}} \mathrm{s}\right)$ for VOCs in low organic carbon sediments 
estimated with the use of field data with those in the literature; and the field measurement of the diffusion of VOCs from contaminated aquifers into adjoining aquitards.

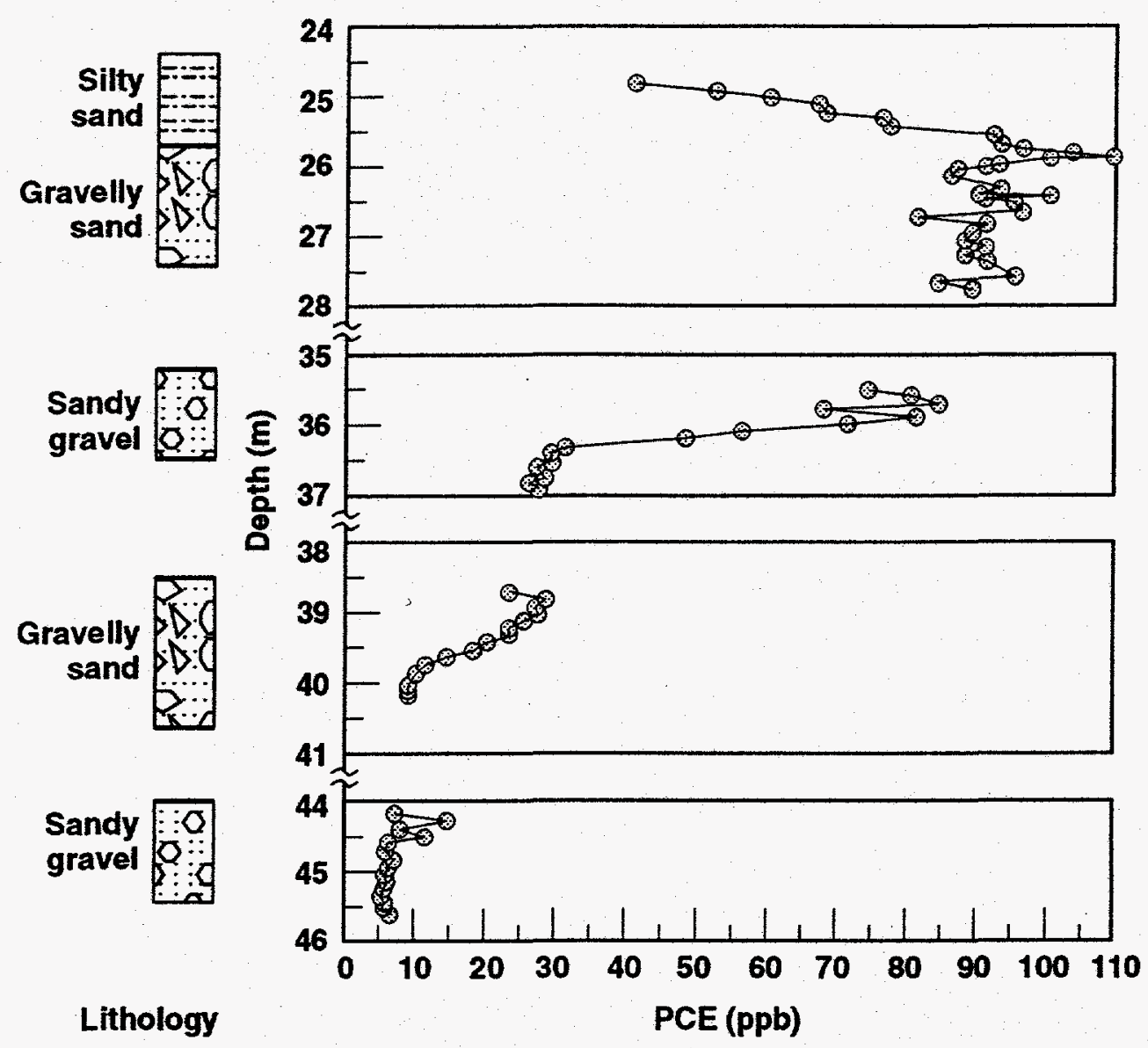

Figure 3. A profile of PCE in Well W-415 at LLNL. Data points are limited to the top four permeable zones.

A column experiment is underway, conducted under more rigorous conditions than the first experiment. The column itself is a glass and teflon chromatography column, the apparatus has been carefully designed and constructed to minimize volatile losses during the experiment, and the analyses of the VOCs will be performed by gas chromatography. The column will be packed with a fine-grained, low organic carbon sand and four VOCs of differing octanol/water partitioning coefficients will be simultaneously passed through the column at a concentration of $300 \mathrm{ppb}$ each. The chemicals are trichloroethylene (TCE), tetrachloroethylene ( $\mathrm{PCE})$, chloroform $\left(\mathrm{CHCl}_{3}\right)$, and carbon tetrachloride $\left(\mathrm{CCl}_{4}\right)$. The breakthrough curves for each of the VOCs will be plotted along 
with a conservative tracer and the retardation of the leading edge of each of the individual plumes will be calculated. When the column reaches or approaches equilibrium, the VOC containing influent will be replaced with fresh water, the experiment will continue, and the cleanup curves will be plotted. The experiment will proceed until the VOC concentrations are well out on the asymptotic part of the cleanup curve. The retardation of the VOCs on the trailing edge of the respective plumes will be calculated and compared to the leading edge retardation in an attempt to observe and quantify any retardation/release hysteresis.

A diffusion apparatus is being designed in an attempt to measure the diffusion of VOCs dissolved in water into sediments of differing geologic characteristics. Continuing searches of the literature have not yet uncovered any experimental work in this area, for VOCs under saturated conditions. This experiment will direct water, containing the same four VOCs used in the column experiment above, over vials packed with sands, silts, and clays. Five different sediments in quadruplicate vials will be included in each of eight modular trays plumbed in parallel. Water containing the VOCs will continually flow over the tops of the vials. At various times during the experiment, probably at one month intervals, a tray will be removed from the system and the vials analyzed for VOC content. The results of the experiment will be compared to the existing theoretical models of diffusion of VOCs in porous media which include the diffusivity of the chemical and tortuosity of the sediment. The objective will be to evaluate the relative magnitude of diffusion into sediments of varying grain size.

A twenty meter long DMLS is being assembled for deployment in well W-415 at LLNL. The DMLS will have cells at $5 \mathrm{~cm}$ intervals through the entire screened area of the well shown in Figure 3. The purpose of this experiment will be to measure the transport of TCE and PCE across the geologic contacts between the permeable zones and their bounding aquitards. I expect to measure the extent of contaminant transport across these contacts to evaluate the importance of the aquitards as sinks for contaminants during the contamination stage and as sources during the cleanup stage. 


\section{Present understanding and hypotheses}

Retardation of VOCs in low organic carbon sediments is commonly thought to be primarily the result of sorption, and the studies at the Borden aquifer were all based on this assumption (Curtis et al., 1986). While sorption may be one of the mechanisms of the apparent retardation of contaminant plumes, there are a number of others that may be significant. Some of these are (not in priority order): hydrodynamic dispersion, abiotic and/or biotic degradation, matrix diffusion, partitioning to organic carbon, and entrapment/retention of the contaminant in constricted or deadend pores in permeable sediments or in the slower moving waters in less permeable materials. Since $K_{d}$ is the only significant variable in the retardation equation (Eq. 1), all of these mechanisms must be included in any complete definition of $\mathrm{K}_{\mathrm{d}}$. Sorption itself is a process that is not simply described for non-polar hydrophobic compounds such as the VOCs studied in this research. The conditions under which sorption can be described as an equilibrium or a nonequilibrium process, remain controversial, as does the role of sorption/desorption hysteresis. The hysteresis described here refers to the rate of desorption being slower than the rate of sorption. The expression of this phenomena may be seen in the shape of the cleanup curve. When cleanup begins there is a rapid decrease in contaminant concentration followed by a flattening or tailing of the curve as it becomes asymptotic. In addition, the variability of contaminant concentration in the ground water confounds the confident prediction of the effect of any of these processes.

VOCs are non-polar, or only slightly polar, and must compete with polar water molecules for sorption sites on the charged surfaces of the aquifer solids. This characteristic of VOCs explains why their $\mathrm{K}_{\mathrm{d}} \mathrm{s}$ are so low and why the understanding of their sorption kinetics is so much more complex than that of polar metallic ion contaminants. It also helps to explain why the relative importance of diffusion of VOCs into less mobile pores in the aquifer and into finer-grained sediments within or bounding the aquifer, may be of major significance. It is possible that I will find that sorption is only a minor factor in the retardation of VOCs under these conditions and that the primary retarding factors are diffusion controlled. 
Wilson (1995) has described tailing of contaminant concentrations during cleanup as being partially attributed to slow bleeding of contaminants from aquifer heterogeneities controlled by diffusion. Farrell and Reinhard (1994) have also suggested that there is rapid removal of contaminants from the macroscale porosity between sediment grains, and slow removal controlled by diffusion from the micropores that occur within grains. However, to date, the scale of the geologic features which may sequester contaminants and then slowly allow them to re-enter the ground water causing the asymptotic portion of the cleanup curve, has yet to be established.

My working hypothesis is that the tailing phenomena is caused by small scale heterogeneities and not by large scale lenses within aquifers or by bounding aquitards, especially as the plume moves farther away from its source. Near the source, the contaminants would have passed through, and remained in, aquitards above the aquifer, creating a longer term source of contaminants to the aquifer. Farther away from the source, the contaminants could only enter the aquitards by transport from the aquifers. I plan to demonstrate, in the field, through the use of the DMLS, and in the laboratory, through the column and diffusion experiments, that diffusion limitations prevent significant sequestration of contaminants in large-scale geologic features, except in the immediate vicinity of the source of the contaminants.

Laboratory studies have shown that VOCs have higher $\mathrm{K}_{\mathrm{d}} \mathrm{s}$ in clays than in silts, and higher $\mathrm{K}_{\mathrm{d}} \mathrm{s}$ in silts than in sands (Bishop et al., 1989). However, from the results of my column experiment, my work on estimating $\mathrm{K}_{\mathrm{d}} \mathrm{s}$ from field data, and from the data at the Borden site (Curtis et al., 1986) it appears that there is no significant difference between the $\mathrm{K}_{\mathrm{d}} \mathrm{s}$ for permeable sediments, with low organic carbon, of varying grain size. A possible explanation for this phenomena is that aquifer materials contain enough fine-grained sediments or enough of a controlling mineral that the distribution of the VOCs are "buffered" such that the $K_{d}$ appears to be not affected by the variable grain size of the sediment. Alternatively, it may be that the density of mesopores or micropores, proposed by Farrell and Reinhard (1994) may be very similar in all aquifer materials regardless of their grain size, and that the $\mathrm{K}_{\mathrm{d}}$ determined from retardation is primarily a function of diffusion controlled sequestration of contaminants in these smaller pores. 
Finally, sorption/desorption of VOCs on low organic carbon sediments has been variously reported as reversible (Karickhoff, 1984; Mackay et al., 1986) and as hysteretic (Bahr, 1989; Domenico and Schwartz, 1990; Mackay et al., 1986). I suggest that one possible explanation for this dichotomy is that the sorption/desorption $\mathrm{K}_{\mathrm{d}}$ mechanism is indeed an equilibrium process and is completely and instantaneously reversible, while the diffusion controlled $\mathrm{K}_{\mathrm{d}}$ mechanisms respond differently at different concentrations. It is probable that both of these mechanisms are at work. The ability to discriminate between them and to measure the kinetics of each, is critical to understanding the transport of VOCs in ground water.

\section{References}

Angel, S. M., Ridley, M. N., Langry, K., Kulp, T. J., Myrick, M. L. 1989. New developments and applications of fiber-optic sensors. In: Murray, R.W., Dessy, R.E., Heineman, W.R., Janata, J., Seitz, W.R., eds. American Chemical Society Symposium Series 403. Washington, DC: American Chemical Society. 23:345.

Bahr, J.M. 1989. Analysis of nonequilibrium desorption of volatile organics during field test of aquifer decontamination. J. Contam. Hydrol., 4: 205-222.

Bishop, D.J., J. P. Knezovich, and D.W. Rice, Jr. 1989. Sorption studies of VOCs related to soil/Ground water contamination at LLNL. Lawrence Livermore National Laboratory, Livermore, CA. (UCID-21651).

Curtis, G.P., Roberts, P.V., and Reinhard, M. 1986. A natural gradient experiment on solute transport in a sand aquifer 4. Sorption of organic solutes and its influence on mobility. Water Resources Research, Vol. 22, No. 13, pp. 2059-2067.

Domenico, P.A., Schwartz, F.W. 1990. Physical and chemical hydrogeology. New York: John Wiley \& Sons. 
Farrell, J and Reinhard, M. 1994. Desorption of halogenated organics from model solids, sediments, and soil under unsaturated conditions. 1. Isotherms and 2. Kinetics. Environ. Sci. Technol. (28), 53-72.

Freeze, R.A., Cherry, J. A. 1979. Groundwater. New Jersey: Prentice-Hall, Inc.

Hoffman, F. 1993a. A strategy for improving pump and treat ground water remediation. in Avogadro, A. and Ragaini, R.C. (eds.) Technologies for Environmental Cleanup: Soil and Groundwater. Kluwer Academic Publishers.

Hoffman, F. 1993b, Ground Water Remediation Using "Smart Pump and Treat". Ground Water, Vol. 31 (1). p. 98-106.

Hoffman, F., and M. D. Dresen. 1990. A method to evaluate the vertical distribution of VOCs in ground water in a single borehole. Ground Water Monitoring Review. 10(2), 95-100.

Hoffman, F., Z. Pearl and M. Magaritz. 1993. Evaluation of flow characteristics of a sand column using magnetic resonance imaging. Submitted to the Journal of Contaminant Hydrology, July 1993. Currently under revision.

Istok, J.D., and Humphrey, M.D. 1993. Buoyancy-induced flow in groundwater at small relative densities: Implications for dispersivity determinations using tracer tests. Unpublished manuscript. Oregon State University, Corvallis, OR.

Karickhoff, S. W. 1984. Organic pollutant sorption in aquatic systems. J. Hydraul. Eng., 110(6), 707-734.

Mackay, D. M., D. L. Freyberg, and P. V. Roberts. 1986. A natural gradient experiment on solute transport in a sand aquifer: 1. Approach and overview of plume movement. Water Resources Research, 22(13), 2017-2029.

Milanovich, F.P., Daley, P.F., Langry, K., Colston Jr., B.W., Brown, S.B., Angel, S.M. 1991. A fiberoptic sensor for the continuous monitoring of chlorinated hydrocarbons. Proc. Second International Conference for Field Screening Methods for Hazardous Wastes and Toxic Chemicals. Feb. 12-14, 1991. Las Vegas, NV: EPA p 43-48. 
Piwoni, M. D., Bannerjee, P. 1989. Sorption of volatile organic solvents from aqueous solution onto subsurface solids. J. Contam. Hydrol., 4:162-179.

Roberts, P.V., Goltz, M.N., Mackay, D.M. 1986. A natural gradient experiment on solute transport in a sand aquifer: 3 . Retardation estimates and mass balances for organic solutes. Water Resources Research. Vol. 22:13 p. 2047-2058.

Ronen, D., M. Magaritz, H. Gvirtzman, and W. Garner. 1987. Microscale chemical heterogeneity in groundwater. J. of Hydrol. 92, p. 173-178.

Schincariol, R. A. and Schwartz, F.W. 1990. An experimental Investigation of variable density flow and mixing in homogeneous and heterogeneous media. Water Resources Research, Vol. 26, No. 10: $2317-2329$.

Schwarzenbach, R. P., Giger, W. 1985. Behavior and fate of halogenated hydrocarbons in ground water. In: Ward, C. H., Giger, W., McCarty, P. L., eds. Ground Water Quality, New York: Wiley-Interscience.

Travis, C. C. and C. B. Doty. 1990. Can contaminated aquifers at Superfund sites be remediated? Environ. Sci. Technol., v. 24, no. 10.

U.S. Environmental Protection Agency. 1989. Evaluation of groundwater extraction remedies. EPA/504/0289/054.

Wilson, J. L. 1995. Removal of aqueous phase dissolved contamination: Non-chemically enhanced pump and treat. in "Subsurface Restoration", H. Ward, J. Cherry, and M. Scalf Eds., in press. Lewis Publishers, Boca Raton, Florida. 